\title{
ПРОЕКТИРОВАНИЕ ПАКЕТА СМАРТ-КОНТРАКТОВ ДЛЯ ОБЕСПЕЧЕНИЯ ЭКОНОМИЧЕСКОЙ БЕЗОПАСНОСТИ СУБЪЕКТОВ ИПОТЕЧНОГО КЛАСТЕРА С ИСПОЛЬЗОВАНИЕМ МЕТОДОВ WАLLЕТАРІ БЛОКЧЕЙН СЕТИ СБЕРБАНКА"
}

\author{
(c) 2021 Бурков Алексей Владимирович
}

доктор экономических наук, профессор кафедры прикладной статистики и информатики Марийский государственный университет, Россия, Республика Марий Эл, Йошкар-Ола E-mail: alexey.burkov@gmail.com

Современный рынок ипотечного кредитования интенсивно развивается и, как следствие, требует разработки и внедрения новых инструментов сопровождения процесса кредитования. В данной статье рассматривается пример создания системы по выдаче ипотеки, которая может быть создана с использованием блокчейн-библиотеки WalletAPI от Сбербанка. Также рассматривается блокчейнплатформа Сбербанка, ее особенности и возможности, основные методы библиотеки WalletAPI, применимые в области ипотечного кредитования.

Ключевые слова: ипотека, ипотечный токен, депозитарий, криптографическая защита, юридическая чистота, аккредитив, Росреестр, идентификация, Сбербанк, блокчейн токен, CNFT, WalletAPI, реестр, ID, эмитент, КриптоПро.

Блокчейн, как центральный инструмент Четвертой промышленной революции, на наш взгляд, заслуживает пристального внимания с точки зрения перспектив его применения в сфере ипотечного кредитования. Блокчейн технология является перспективной возможностью оптимизировать процесс приобретения жилья в ипотеку, сохранив затраты финансовых организаций на обеспечение процесса кредитования.

Согласно оценке экспертов, технология блокчейн потенциально может сэкономить до двух миллиардов долларов на ипотечном рынке. Технология способна увеличить прозрачность ипотечной сделки и отслеживать все действия её участников. Более того, технология блокчейн, во-первых, предполагает реализацию прав всех субъектов сделки по контролю за ее совершением, в том числе за движением денежных средств в он-лайн режиме; во-вторых, формирование безопасного пространства для участников сделки за счет использования криптографической защиты.

Технология блокчейн применительно к сфере ипотечного кредитования позволяет:

- снизить риски фальсификации данных за счет прозрачности и применения криптографических методов,
- оптимизировать затраты и сократить сроки ожидания одобрения кредита.

Для банков и государственных структур внедрение технологии блокчейн предоставляет возможность создать унифицированную платформы для регистрации и совершения ипотечных сделок.

Рассмотрим основные этапы оформления ипотеки без использования технологии блокчейн:

1. Подача клиентом заявки на ипотеку.

2. Проверка кредитной истории клиента.

3. Поиск недвижимости.

4. Сбор документов по недвижимости.

5. Одобрение недвижимости банком.

6. Сделка и подписание кредитных документов.

7. Регистрация сделки.

8. Расчеты между покупателем и продавцом.

Для внедрения технологии блокчейн необходимо разработать набор смарт-контрактов для автоматизации процесса оформления ипотеки. Смарт-контракт - это автоматически исполняемая распределенная программа, выполняемая в блокчейн-сети. Набор смарт-контрактов, автоматизирующий процесс оформления ипотеки зависит от специфики конкретной организации.

Минимальный набор необходимых смарт-контрактов состоит из четырех смарт-

\footnotetext{
Работа выполнена при финансовой поддержке РФФИ в рамках научного проекта № 20-010-00472 А «Методология применения систем распределенных реестров (технологии блокчейн) в обеспечении экономической безопасности субъектов ипотечного кластера»
} 


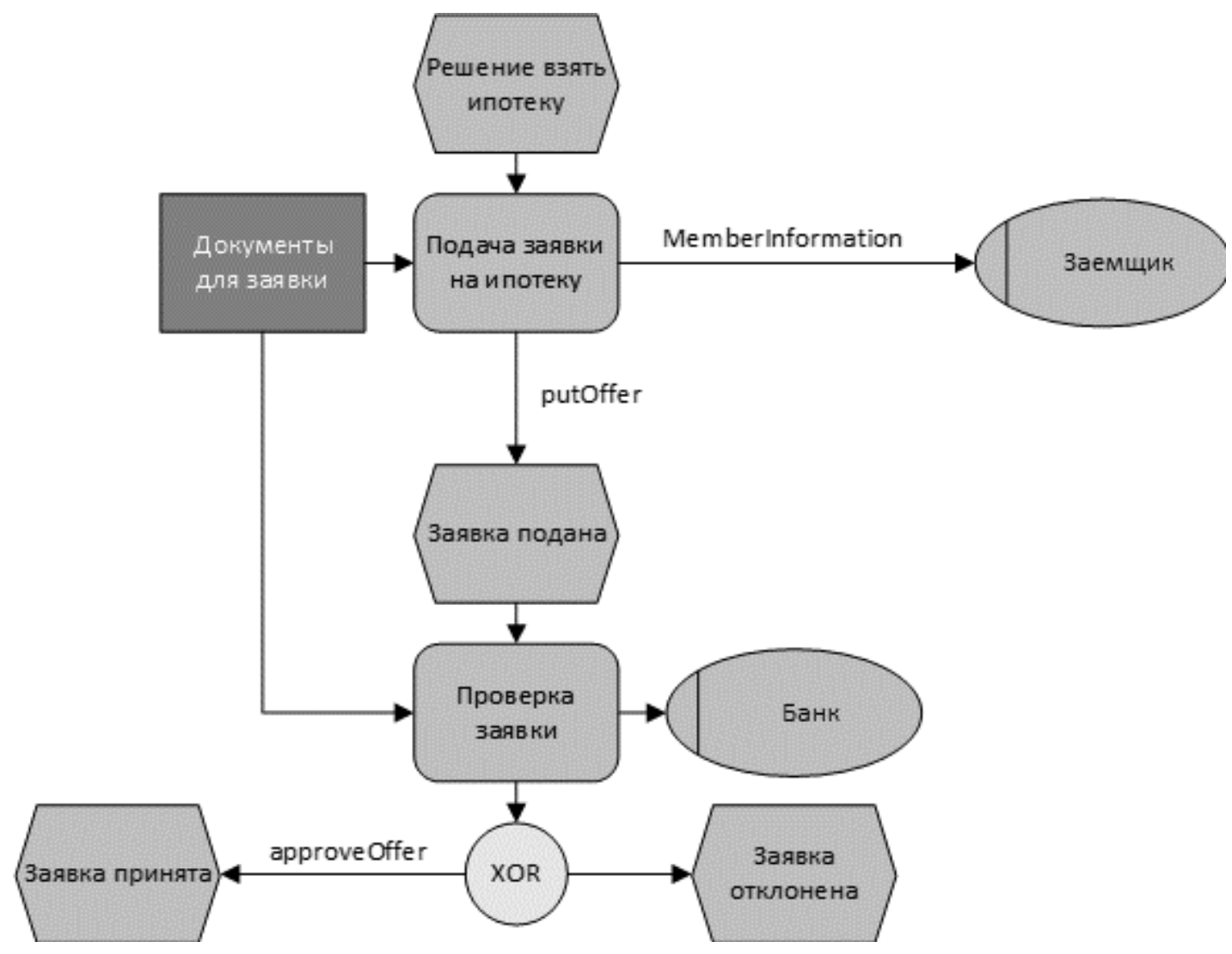

Puc. 1. Блок-схема процесса подачи и проверки документов заемщика

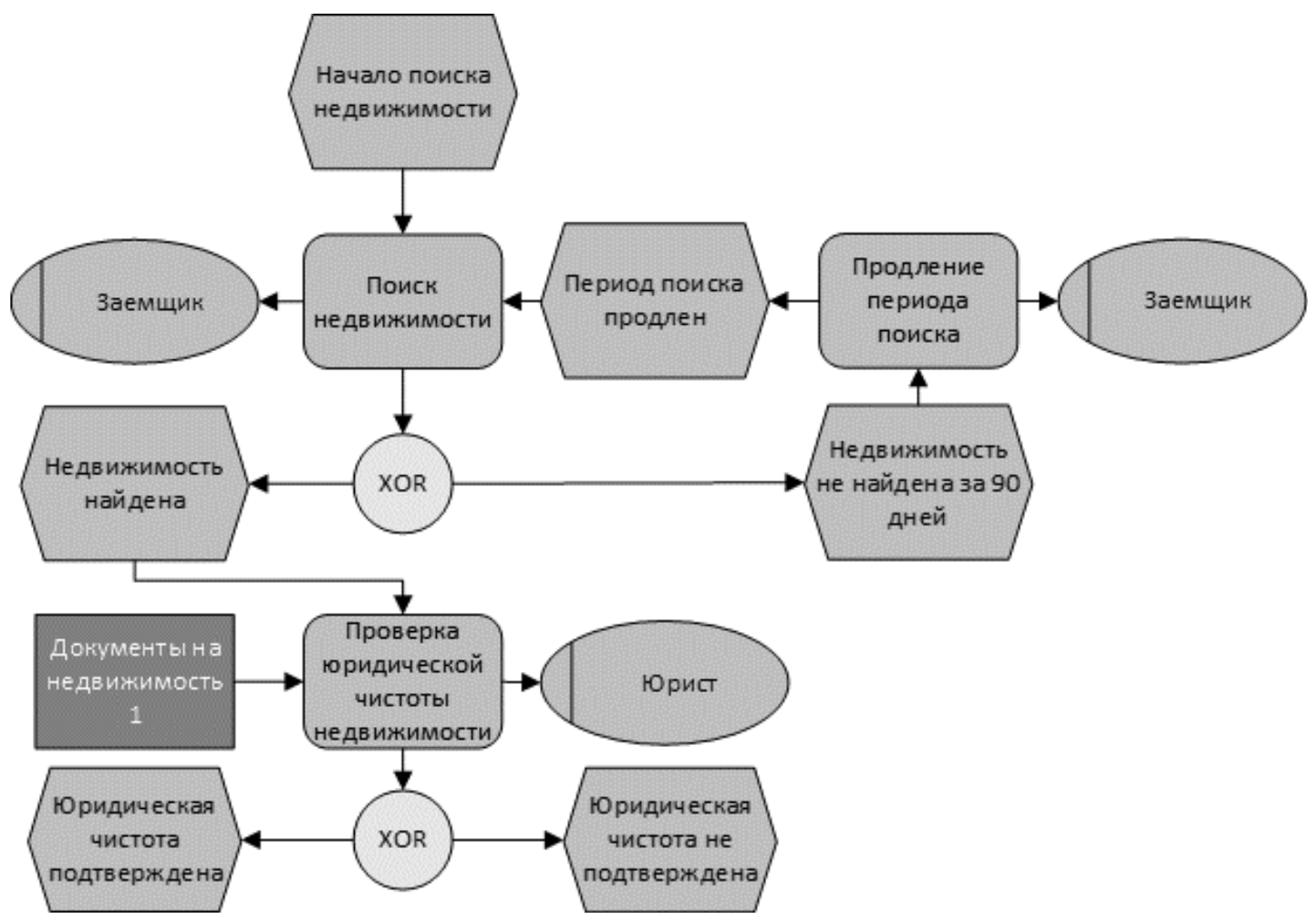

Puc. 2. Блок-схема процесса поиска недвижимости и проверки её юридической чистоты 
контрактов:

- Смарт-контракт для обработки заявки на ипотеку.

- Смарт-контракт для проверки юридической чистоты.

- Смарт-контракт для сбора документов.

- Смарт-контракт для регистрации сделки и расчетов.

Рассмотрим данные смарт-контракты более подробно. На рисунке 1 представлен смартконтракт, предназначенный для обработки заявки на ипотеку. Данный смарт-контракт предполагает дистанционный формат обслуживания.

Для подачи заявки клиент заполняет анкету в своем личном кабинете на сайте банка и прикрепляет необходимые документы: паспорт, справку 2-НДФЛ и заверенную копию трудовой книжки. Смарт-контракт в автоматическом режиме проверяет достоверность данных, используя единый распределенный реестр данных. Поставщиком данных для реестра могут являться другие банки, федеральная налоговая служба или национальное бюро кредитных историй.

После успешной проверки данных и одобрения банком, у клиента есть некоторое время для поиска подходящей недвижимости.

Теперь рассмотрим смарт-контракт для проверки корректности сделки с точки зрения юридических формальностей (Рис. 2). После выбора квартиры на вторичном рынке, требуется проверка ее юридической чистоты.

Вторичный рынок жилья характеризуется сложной историей каждой квартиры. Квартира в прошлом до совершения ипотечной сделки может быть неоднократно предметом договора купли-продажи. Каждая сделка в этой истории является дополнительным фактором риска для участников сделки. С целью анализа истории подобных «цепочек» сделок в отношении объекта недвижимости проводится правовая экспертиза. Применение смарт-контракта для проверки юридической чистоты может упростить проверку объектов недвижимости. Поиск данных об объекте может проводиться по единому реестру банков и госструктур.

Следующий смарт-контракт, который мы рассмотрим - это смарт-контракт для сбора документов (Рис. 3). Данный смарт-контракт должен аккумулировать все документы от клиента и банка и записывать их в единый реестр.

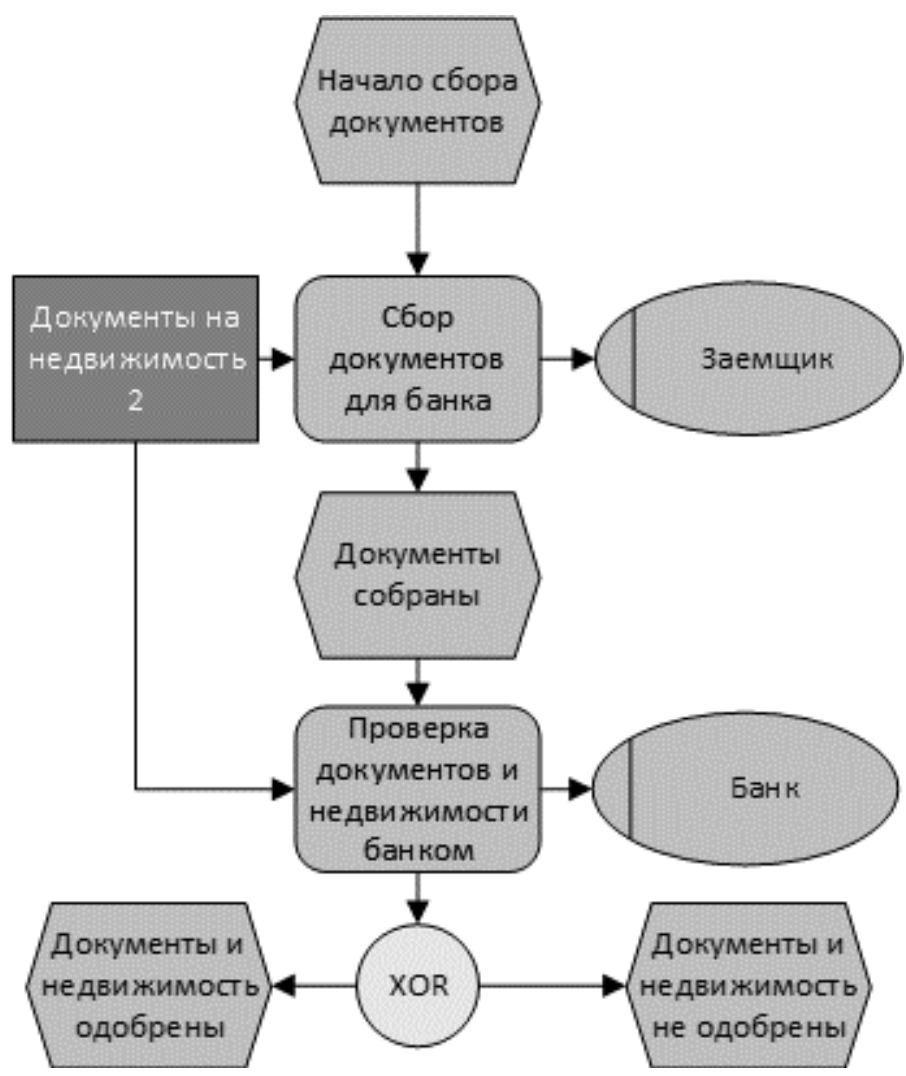

Puc. 3. Блок-схема процесса сбора и проверки документов на приобретаемую недвижимость 
К таким документам могут относиться:

- договор купли-продажи,

- документы из БТИ (выписка из домовой книги, кадастровый паспорт),

- документы от застройщика/продавца (технический паспорт, свидетельства о праве собственности, прочее),

- документ об оценки недвижимости.

Применение технологии блокчейн обеспечит достоверность данных и исключит их подделку.

Наконец, рассмотрим смарт-контракт для регистрации сделки и расчетов (Рис. 4). На данном этапе сделки смарт-контракт позволяет обеспечить интересы кредитора, не допустив причинение ущерба предмету залога.

В настоящее время ипотечный договор заключается в письменном виде, а также должен пройти процедуру государственной регистрации по месту нахождения имущества.

Смарт-контракт для регистрации сделки в едином реестре должен автоматически передавать данные в Росреестр, при этом подпись документов может быть осуществлена с использованием электронной подписи.

В договоре должны быть обязательно указаны предмет ипотеки (объект недвижимости), его адрес и оценочная стоимость, данные сторон договора, сумма кредита, выдаваемого под залог, права и обязанности участников, а также срок погашения кредита. Далее происходит автоматическая регистрация сделки в МФЦ.

Теперь рассмотрим возможную схему расчета между покупателем и продавцом. Есть несколько основных способов расчета за приобретенную квартиру: 1) аккредитив, предусматривающий предварительный перевод денежных средств покупателем на специальный банковский счет до успешной регистрации сделки; 2) банковская ячейка позволяет передавать наличные денежные средства (покупатель в присутствии продавца помещает наличные в ячейку и она закрывается); 3) прямой расчет наличными или безналичными средствами; 4) сервис безопасных расчетов банка. Так, у Сбербанка существует сервис безопасных взаиморасчетов между покупателем и продавцом. Покупатель переводит средства на специальный счет «Центра недвижимости от Сбербанка». Продавец получает денежные средства только после подтверждения регистрации сделки со стороны
Росреестра.

Теперь, более подробно, рассмотрим блокчейн платформу Сбербанка. 20 мая 2021 года Сбербанк представил свою блокчейн-платформу, данная платформа станет доступной для всего сообщества разработчиков.

Для разработчиков стали доступны:

- полнофункциональный WalletAPI для разработки,

- библиотека для работы с токенами,

- создание лёгких клиентских приложений, работающих напрямую с блокчейн-платформой.

Для совершения сделок на платформе Сбербанка используется специальная расчётная единица, что позволяет производить расчёты в смарт-контрактах в рублях.

Платформа реализована на базе оpen source решения HyperLedger Fabric от The Linux Foundation, с использованием Российских криптографических алгоритмов шифрования, хэширования и электронной подписи компании КриптоПро. Платформа интегрирована в сервисы Сбербанка, что позволяет связать исполнение смарт-контрактов с платежами в рублях.

В заключение рассмотрим работу с библиотекой пошагово:

- На этапе подачи заявки на ипотеку заемщик передает в систему блок данных "Member Information" (Рис. 1).

- Применяем метод putOffer (Рис. 1). Данный метод публикует оффер (предложение) в открытом доступе, оффер содержит предложение обменять один токен на другой. До применения данного метода необходимо создать токены покупателя и продавца. Для этого возможно использовать методы registerTokenType (зарегистрировать токен) и issue (опубликовать токен).

- Если заявка принята, то применяем метод approveOffer (Рис. 1). Данный метод инициирует принятие предложения (оффер).

- При завершении сделки мы передаем токены от покупателя к продавцу при помощи метода sendToken (Рис. 4).

- По окончании сделки необходимо уничтожить созданные токены методом burnToken (Рис. 4).

В итоге, внедрение технологии блокчейн позволит сделать процесс ипотечного кредитования позволить сделать этот процесс удобней, быстрее, прозрачнее и безопаснее. 


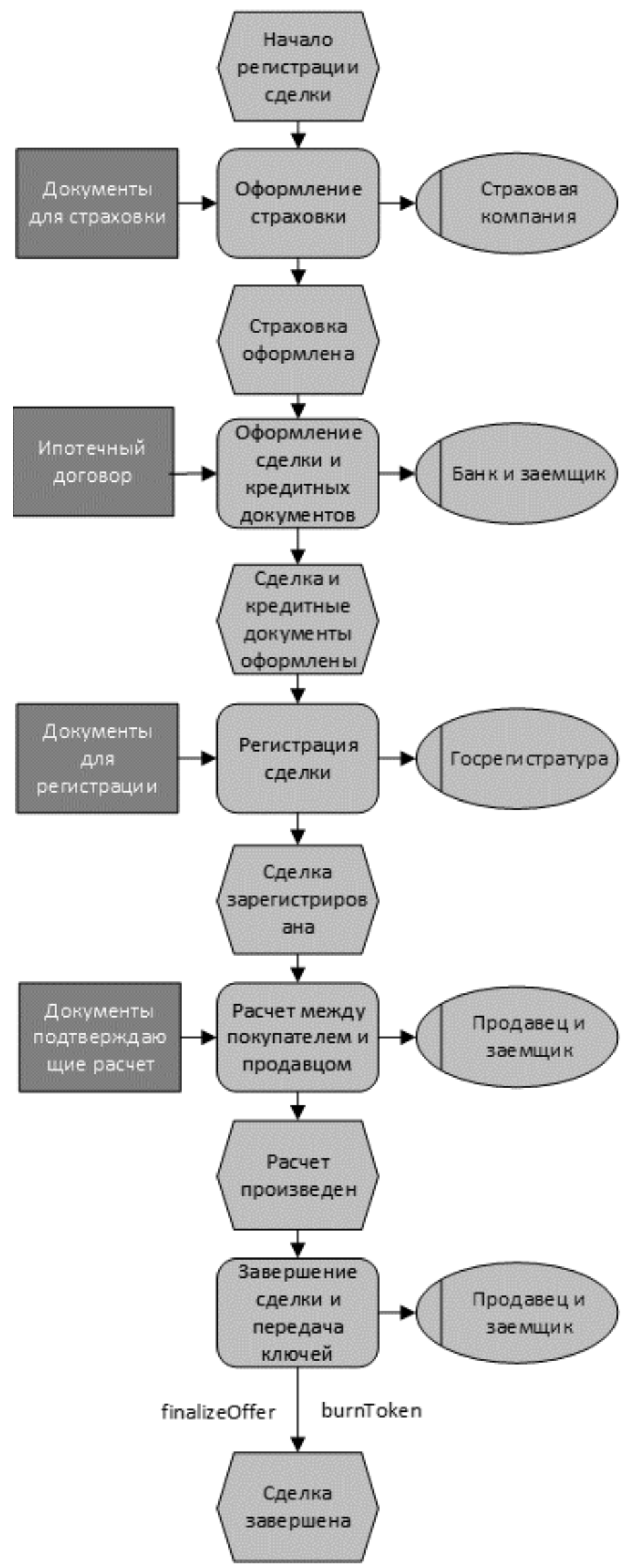

Puc. 4. Блок-схема процесса регистрации сделки и расчетов 


\section{Библиографический список}

1. Основные этапы покупки квартиры в ипотеку. URL: https://promo.domclick.ru/osnovnye-etapy-oformleniyaipoteki

2. Блокчейн и ипотека. URL: https://blogs.forbes.ru/2020/09/15/blokchejn-i-ipoteka-kak-optimizirovat-38-mlrd/

3. Сберанк: официальный сайт. URL: https://www.sberbank.ru/ru/person/promo/blockchain

4. Документация нативной библиотеки WalletAPI. 